\title{
Microwave-Assisted Preparation of Magnetic Citric Acid-Sugarcane Bagasse for Removal of Textile Dyes
}

\author{
Nguyen Thi Hong Anh', Tran Thanh Phuc', Tran Nguyen Minh An ${ }^{2}$, \\ Pho Quoc Hue ${ }^{2}$, and Nguyen Van Cuong, ${ }^{2 *}$ \\ ${ }^{1}$ Faculty of Chemical Engineering, Ho Chi Minh City University of Food Industry, \\ 140 Le Trong Tan, Tay Thanh Ward, Tan Phu District, Ho Chi Minh City, Vietnam \\ ${ }^{2}$ Faculty of Chemical Engineering, Industrial University of Ho Chi Minh City, \\ 12 Nguyen Van Bao, Ward 4, Go Vap District, Ho Chi Minh City, Vietnam
}

\section{*Corresponding author:}

email:nvc@iuh.edu.vn

Received: August 13, 2019

Accepted: October 27, 2019

DOI: $10.22146 /$ ijc. 48713

\begin{abstract}
Wastewater from industries has been a serious issue that both manufactures and authorities raise concerns since it brings tremendous demerits to the surrounding environment and human well-being. Therefore, an appropriate treatment method should be applied before being discharged into the environment. In this paper, sugarcane bagasse was modified with citric acid and then used to load the suspension of $\mathrm{Fe}_{3} \mathrm{O}_{4}$ nanoparticles to form a nanocomposite of magnetic citric acid-modified sugarcane bagasse. The properties of prepared materials were investigated by a variety of modern methods such as X-ray diffraction (XRD), Fourier transforms infrared spectroscopy (FT-IR), Scanning electron microscopy (SEM), Transmission electron microscopy (TEM) and a Vibrating sample magnetometer (VSM). The adsorptive capacity of prepared materials was investigated with methylene blue as the typical adsorbate. The decolonization effectiveness was increased with increasing contact time and declined with rising initial dye concentration. The higher removal efficiency was observed for the basic medium in comparison with the acidic medium. Additionally, the results showed that more than $12.42 \mathrm{mg} / \mathrm{g}$ (98\%) of cationic yellow 51, and basic red 46 dyes were removed after $30 \mathrm{~min}$.
\end{abstract}

Keywords: sugarcane bagasse; adsorption; microwave; nanocomposites; textile dyes

\section{- INTRODUCTION}

Industrial wastewater is defined as water that has been utilized for making commercial goods before treatment, which consists of plenty of toxic contaminants and usuch as indecomposable organic dyes and heavy metals [1]. Annually, it is estimated that more than 80 percent of the world's wastewater is released into the environment without preliminary treatment or recycling [2]. Apart from that, it is believed that most of the industrial sectors concentrate nearby coastal areas where sewage can be leaked into the ocean with ease and that the exploitation of fossil fuels has recently witnessed a dramatic increase due to global economic growth. As a result, the water, environment from surface water to groundwater in these areas, is investigated to be severely polluted. Therefore, in addition to raising the awareness of people about environment protection, tightening the management of the environment, finding an effective way to eliminate pollutants has a great significance.

Among industrial sectors, textile industries have been considered to be one of the sources of water pollution as they consume large quantities of water and chemicals, especially in dyeing and finishing processes [3]. An approximation of $10-15 \%$ of the used dyes have vanished during the dyeing processes [4-5]. Current methods have been used for the treatment of this type of dye-related wastewater, which comprises precipitation, coagulation/flotation, sedimentation, flotation, filtration, membrane processes, electrochemical techniques, advanced oxidation, ion exchange, biological treatment, chemical reactions, and adsorption [6-8]. In particular, 
biological treatment methods are preferable due to their treatment efficiency in the long run, but they also have drawbacks such as the uncontrollable process of ventilation, ease of smell [9]. Physical or chemical processes are often used, but the high cost of these processes is disadvantageous. The combination of various methods is usually used to treat real textile wastewater [10]. Meanwhile, among wastewater treatment methods, adsorption is one of the most applicable techniques used to remove pollutants from sewage because of several reasons related to cost-efficiency, easy-to-fabricate, ecofriendliness, and the ability to recycle. It is reported that there have various types of materials being used to remove contaminants from wastewater, among which are activated charcoal, chitosan, orange peels, porous materials, etc [11-15]. One of the disadvantages that make activated carbon less useful is the capability to recycle. From this perspective, a cost-efficient adsorbent that derives from agricultural residues combined with magnetic nanoparticles is used to remove pollutants in water with feasible recyclable ability, namely a nanocomposite of magnetic citric acid-modified sugarcane garbage [16-18].

It is reported that microwave irradiation was used in the chemical process due to the simple and clean method with high-efficiency energy. Nanoparticle materials have been prepared by microwave-assisted methods with uniform, small, narrow size distributions and high crystalline orders in comparison with nanoparticle synthesized by the conventional heating method [19-21]. Acid modification of material is usually conducted under a reflux condition with high temperature and long reaction time under an oil bath. However, the usage of microwave-assisted modification of materials was reported to reduce the reaction time and high modification efficiency.

In this research, the sugarcane bagasse is used as a matrix in the nanocomposite, which is a by-product of the sugar production process. The sugarcane bagasse and its modification were used as an environmentally friendly adsorbent for the elimination of textile dyes and heavy metals from aqueous solutions [22-23]. With a porous structure, sugarcane bagasse can function as a trap in order to attract dye molecules into its matrix through physical and chemical interaction. There is a limitation in terms of the small particle size of sugarcane bagasse powders, which means that the small particle size of bagasse powders results in the difficulty of collecting after usage. Therefore, it is a huge attractive work to increase the separation property of the adsorbents with tiny size. In recent times, magnetic separation technologies have been giving interests. Magnetic materials can be recovered from an aqueous solution efficiently with an external magnet. Therefore, the magnetic nanoparticles loaded in bagasse matrix has a promising potential to overcome this issue. In addition, the surface of sugarcane bagasse was modified with citric acid under microwave irradiation and also increased the capacity of adsorbing metals and dye molecules.

\section{- EXPERIMENTAL SECTION}

\section{Materials}

Clean sugarcane bagasse was provided from a local sugar mill with a low grade of impurities. Then, the sugarcane bagasse was dried in an oven at a temperature of $105{ }^{\circ} \mathrm{C}$ for $4 \mathrm{~h}$ to remove the water. The resulting material was ground into powders with a particle size of $0.5-1 \mathrm{~mm}$ and kept for further experiments. Reactive red $198(\mathrm{RR} 198)\left(\mathrm{Mw}=983.5, \lambda_{\max }=554 \mathrm{~nm}\right)$, Cationic yellow $51\left(C Y 51 \mathrm{Mw}=403.5, \lambda_{\max }=410 \mathrm{~nm}\right)$, Basic red $46(\mathrm{BS} 46)\left(\mathrm{Mw}=401.312, \lambda_{\max }=532 \mathrm{~nm}\right)$ and Methylene blue $(\mathrm{MB})\left(\mathrm{Mw}=319.86, \lambda_{\max }=664 \mathrm{~nm}\right)$ were provided from Thanh Cong Textile Garment Investment Trading Joint Stock Company. Synthetic industrial wastewater was prepared by dissolving these dyes in distilled water.

\section{Procedure}

\section{Sugarcane bagasse preparation}

Preparation of citric acid-modified sugarcane bagasse (CAS). Sugarcane bagasse (RS, $10 \mathrm{~g}$ ) was modified with $250 \mathrm{~mL}$ citric acid at various concentrations, including $0.1,0.3$, and $0.5 \mathrm{~mol} \mathrm{~L}^{-1}$ under microwave radiation for $10 \mathrm{~min}$. The resulting samples were washed by distilled water until reaching the $\mathrm{pH}$ value of 7 . Afterward, the washed mixture was dried in an oven at a constant temperature of $70^{\circ} \mathrm{C}$ for $12 \mathrm{~h}$ to obtain dried citric acid modified sugarcane (CAS). 
Preparation of magnetic sugarcane bagasse (MCAS). Magnetic sugarcane bagasse was fabricated by adding the citric acid-modified sugarcane bagasse to a suspension of $\mathrm{Fe}_{3} \mathrm{O}_{4}$ nanoparticles with a ratio of 9:1. Briefly, in order to synthesize $\mathrm{Fe}_{3} \mathrm{O}_{4}$ nanoparticles, a given amount of $5.41 \mathrm{~g}$ of $\mathrm{FeCl}_{3} \cdot 6 \mathrm{H}_{2} \mathrm{O}$ and $1.99 \mathrm{~g}$ of $\mathrm{FeCl}_{2} \cdot 4 \mathrm{H}_{2} \mathrm{O}$ were transferred into $150 \mathrm{~mL}$ of distilled water under mechanical stirrer for $30 \mathrm{~min}$. Later on, $4.5 \mathrm{~g}$ of CAS was added to the resulting solution and heated up at $80{ }^{\circ} \mathrm{C}$. Next, magnetic sugarcane bagasse was obtained by adding a dropwise $\mathrm{NaOH}$ solution $\left(0.1 \mathrm{~mol} \mathrm{~L}^{-1}\right)$ and the $\mathrm{pH}$ value of the solution was adjusted to around 11 using $\mathrm{NaOH}$ to obtain nanocomposite. The obtained mixture was stirred mechanically for $6 \mathrm{~h}$. An external magnet was applied in order to collect the nanocomposite. The final nanocomposite was washed with water and ethanol for 5 times and dried in a vacuum oven for $24 \mathrm{~h}$.

\section{Analytical methods}

Fourier transform infrared (FT-IR) analysis of the samples was performed on Tensor 27 -Bruker, Germany in order to determine functional groups of nanocomposites with the scanning wave numbers ranging 400-4000 $\mathrm{cm}^{-1}$. The structural properties of magnetic nanocomposites were investigated using $\mathrm{X}$-ray powder diffraction (XRD) (D8 Advance-Bruker System, Germany). Morphological examination of the nanocomposites was evaluated by using scanning electron microscopy (SEM) (HITACHI-S-4800, Tokyo, Japan). In order to examine the existence of $\mathrm{Fe}_{3} \mathrm{O}_{4}$ nanoparticles in the nanocomposites by characterizing the magnetic properties of materials, a vibrating sample magnetometer (DMS-880) was used with a magnetic field from $-15 \mathrm{k}$ Oe to $15 \mathrm{k}$ Oe at room temperature.

\section{Adsorption experiments}

To investigate the adsorption properties of the prepared materials, batch adsorption studies were prepared using $0.2 \mathrm{~g}$ of adsorbents and $50 \mathrm{~mL}$ various dye solutions at a wide range of initial concentrations of $\mathrm{MB}$ from 30 to $75 \mathrm{mg} \mathrm{L}^{-1}$. At different time intervals, the dye solution was separated using a permanent magnet. The dye concentration at a certain time was determined using a UV-Vis spectrophotometer at a wavelength of $664 \mathrm{~nm}$. In addition, to examine the influence of $\mathrm{pH}$ medium on the adsorption capacity of the prepared materials, the batch adsorption was carried at various $\mathrm{pH}$ values from 3 to 9 with a $50 \mathrm{~mL} \mathrm{MB}$ solution $\left(50 \mathrm{mg} \mathrm{L}^{-1}\right)$. The impact of the mass of adsorbents used $(0.05,0.1,0.2$, and $0.5 \mathrm{~g}$ ) was also determined by carrying out the experiments in the $50 \mathrm{~mL}$ dye solution (concentration of $50 \mathrm{mg} \mathrm{L}^{-1}$ ) for $30 \mathrm{~min}$. Finally, the effect of various dye structures, including RR198, CY51, BS46 (50 $\mathrm{mg} \mathrm{L}^{-1}$ ) on the adsorption capacity of the prepared materials, was performed in a set of $250 \mathrm{~mL}$ Erlenmeyer flasks containing $0.2 \mathrm{~g}$ adsorbent and $50 \mathrm{~mL}$ various dye solutions for $30 \mathrm{~min}$. All of the adsorption experiments were repeated triplicate for the average value and its standard deviation. The yield of adsorption capacity was determined by the following Eq. (1):

$\left(\mathrm{C}_{0}-\mathrm{C}_{\mathrm{e}}\right) / \mathrm{C}_{0} \times 100$

where $\mathrm{C}_{0}$ and $\mathrm{C}_{\mathrm{e}}$ are the initial and equilibrium concentration of dye solution $\left(\mathrm{mg} \mathrm{L}^{-1}\right)$.

\section{- RESULTS AND DISCUSSION}

\section{Characteristic of the Materials}

Fig. 1 represents the FT-IR spectra of samples RS, CAS, and MCAS. The result showed that in three samples, there are three typical absorption bands at 896 , 1160 , and $1031 \mathrm{~cm}^{-1}$, which are assigned to $\beta-(1-4)$ glycosidic bond of cellulose, $\mathrm{C}-\mathrm{O}-\mathrm{C}$ stretching, and $\mathrm{C}-\mathrm{O}$ stretching, accordingly. The absorption bands that represent for $\mathrm{C}=\mathrm{O}$ stretching were observed at 1714 and $1720 \mathrm{~cm}^{-1}$. More interesting, the intensity of these peaks is higher in CAS and MCAS in comparison with RS. It is feasible that the acetylation reaction of carboxylic groups of citric acid and to the hydroxyl group of RS to generate an ester bond could have taken place. Meanwhile, bands at 1320 and $1370 \mathrm{~cm}^{-1}$ in the FT-IR spectrum were attributed to the presence of $\mathrm{C}-\mathrm{H}$ groups. In addition, the lignin associated bands were also depicted at 1511 and $1600 \mathrm{~cm}^{-1}$. Importantly, the band at $580 \mathrm{~cm}^{-1}$ representing the $\mathrm{Fe}-\mathrm{O}$ stretching was found only in the MCAS sample, which means that magnetic nanoparticles exist in the bagasse powders.

XRD results of MCAS and $\mathrm{Fe}_{3} \mathrm{O}_{4}$ nanoparticles were revealed in Fig. 2. As a result, the diffraction spectrum at 16 and $22^{\circ}$ showed the existence of cellulose 


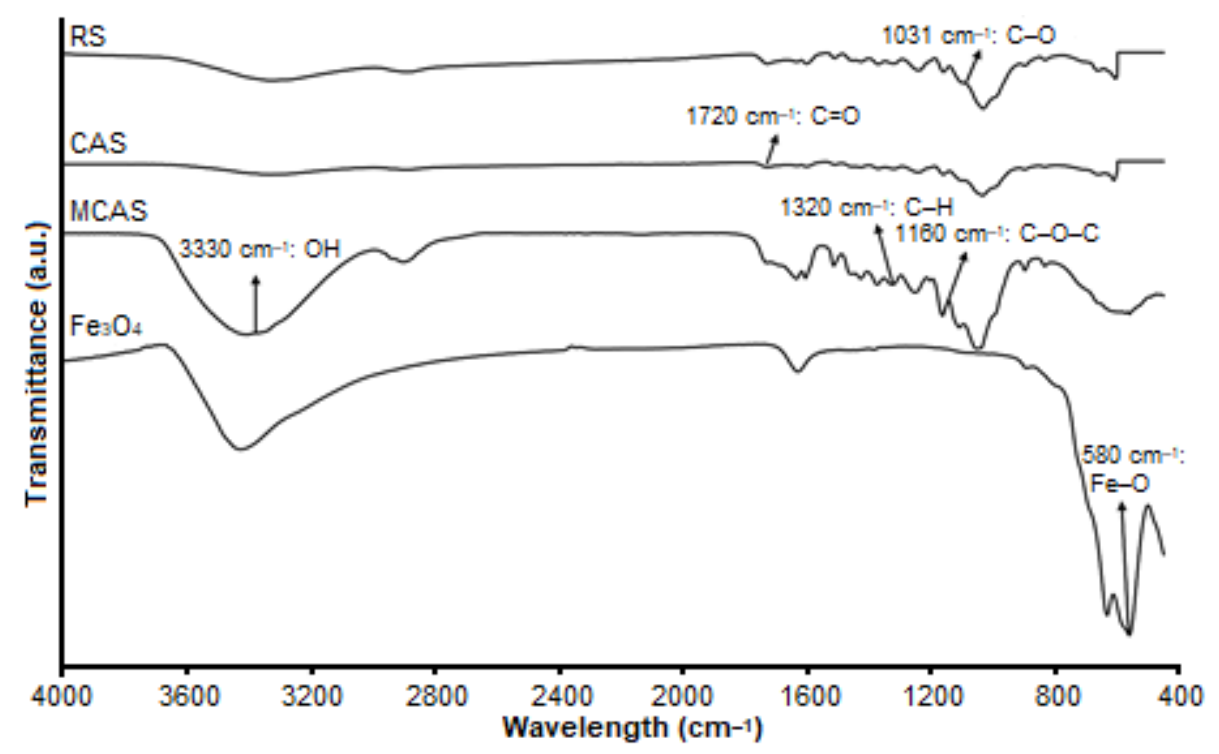

Fig 1. FTIR spectrum of the prepared materials RS, CAS, and MCAS

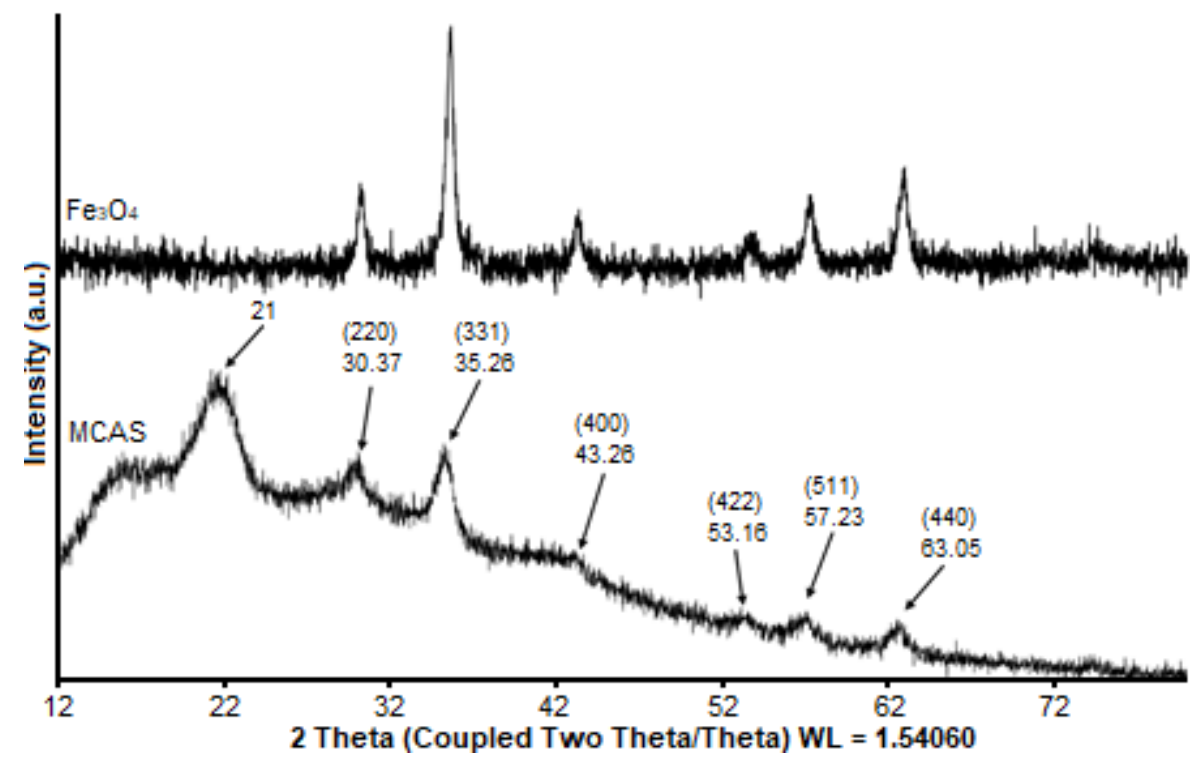

Fig 2. X-ray diffraction (XRD) pattern of $\mathrm{Fe}_{3} \mathrm{O}_{4}$ nanoparticles and MCAS

in MCAS samples. The peaks at $30,35,43,53,57$, and $63^{\circ}$ are corresponding to $\mathrm{Fe}_{3} \mathrm{O}_{4}$ nanoparticles [24]. Moreover, the TEM and SEM images in Fig. 3 confirmed that $\mathrm{Fe}_{3} \mathrm{O}_{4}$ nanoparticles adhered to the bagasse surface. The EDS result of the MCAS sample was also shown in Fig. 4, which depicted that the presence of iron was indicated by two peaks $\mathrm{K}$ of about 6.4 and $7.0 \mathrm{keV}$ and a peak $\mathrm{L}$ of $0.78 \mathrm{keV}$. There was also the existence of other factors of sugarcane bagasse, such as $\mathrm{Si}$ at $1.80 \mathrm{keV}$. Additionally, the magnetization curve (VSM) of MCAS and $\mathrm{Fe}_{3} \mathrm{O}_{4}$ samples were revealed in Fig. 5. The VSM shows that the magnetic saturation of MCAS $(M s=7.26 \mathrm{emu} / \mathrm{g})$ was lower than that of $\mathrm{Fe}_{3} \mathrm{O}_{4}$ nanoparticles $(M \mathrm{~s}=71.0$ $\mathrm{emu} / \mathrm{g}$ ) due to the presence of nonmagnetic organic matter of bagasse. Though $\mathrm{Fe}_{3} \mathrm{O}_{4}$ nanoparticles were dispersed into the bagasse matrix, the magnetic saturation of MCAS was still available with a smaller value. From this result, it is believed that our materials can be recovered from an aqueous solution with an external magnet [12]. 


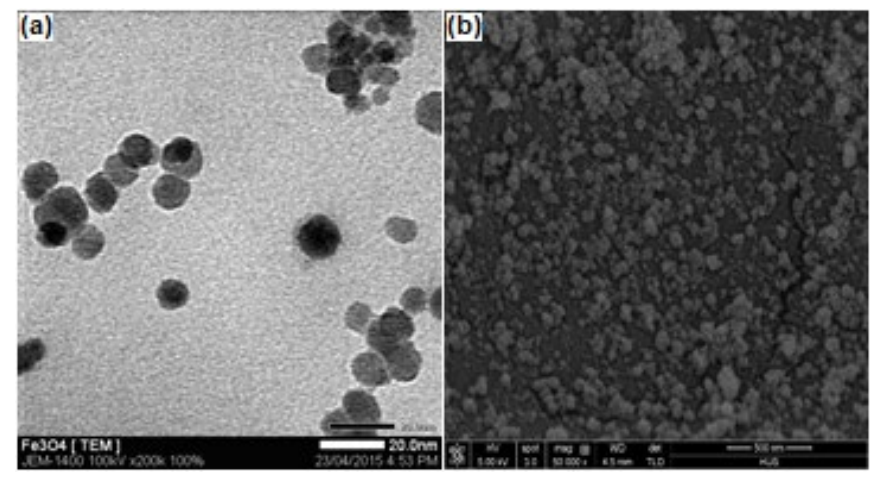

Fig 3. The TEM image of (a) $\mathrm{Fe}_{3} \mathrm{O}_{4}$ nanoparticles and (b) morphological SEM image of the prepared MCAS

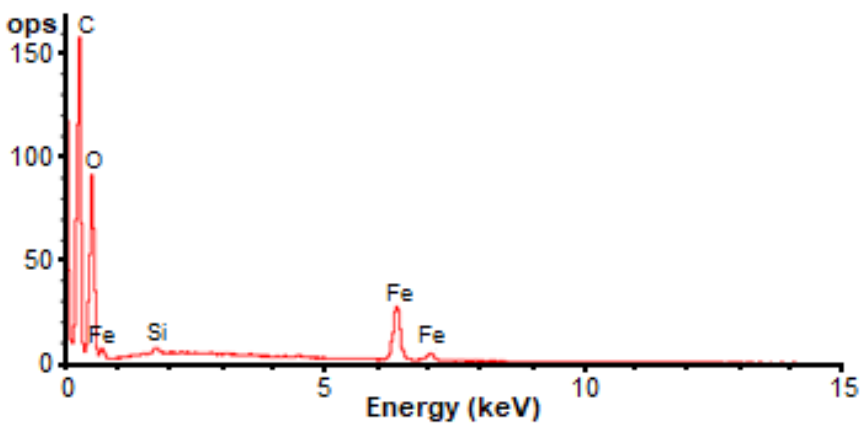

Fig 4. EDS spectra of MCAS

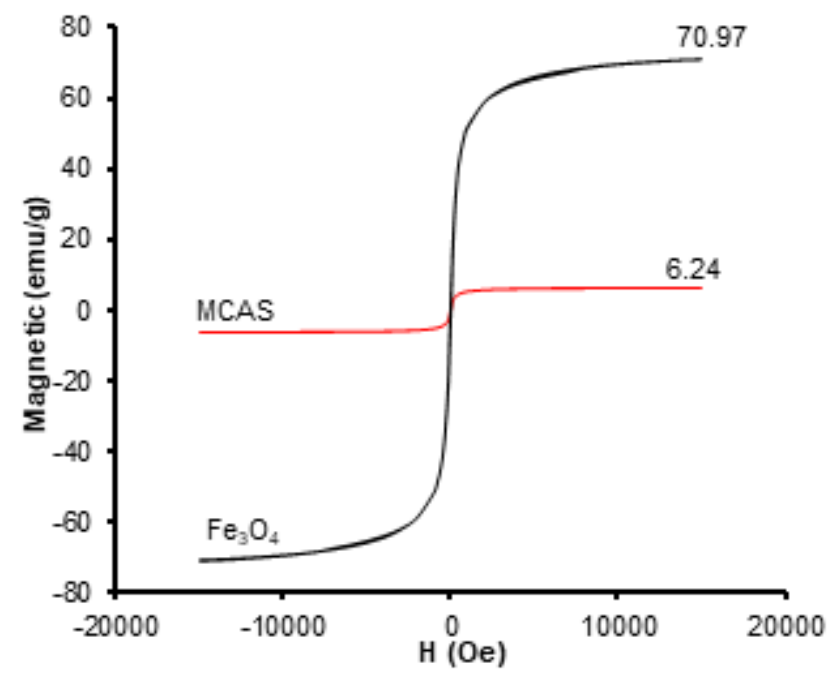

Fig 5. VSM spectra of MCAS and $\mathrm{Fe}_{3} \mathrm{O}_{4}$

\section{Influence of Citric Acid Concentration on MB Adsorption of CAS}

Fig. 6 shows the influence of citric acid concentration on the removal of $\mathrm{MB}$. The results indicated that removal efficiency increased with rising citric acid concentration. The highest adsorption efficiency for MB was 99\% was observed for the concentration of citric acid 0.5 M. The crude sugarcane bagasse gave a much lower adsorption efficiency (66\%) in comparison with citric acid-treated sugarcane bagasse (CAS). This could be explained due to CAS containing more -COO- groups than that of crude sugarcane bagasse [25].

\section{Effect of MCAS Dosage on Adsorption Efficiency of MB}

Fig. 7 showed how the dosage factor of MCAS influenced the adsorption efficiency of MB. As observed,

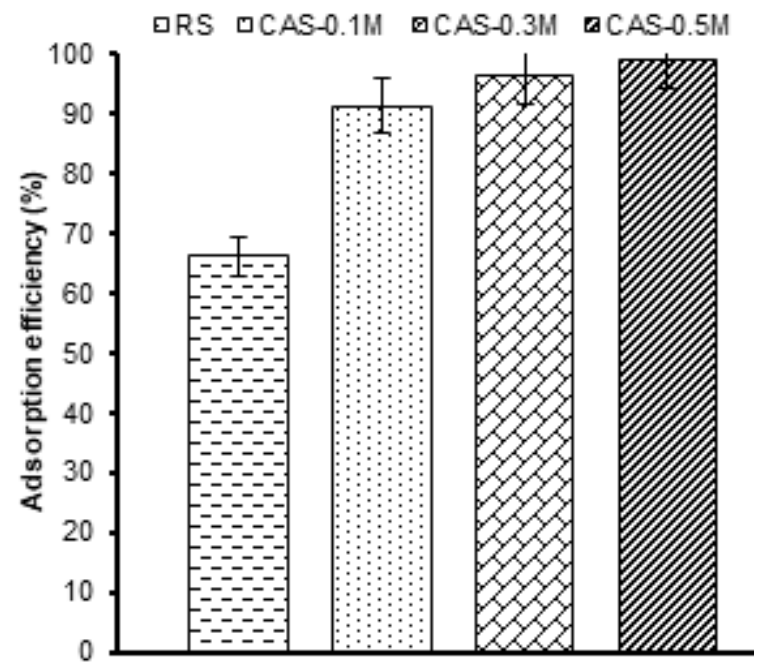

Fig 6. Adsorption efficiency of $\mathrm{MB}$ onto various materials ( $0.2 \mathrm{~g}$ materials; and solution volume: $50 \mathrm{~mL}$ with a concentration of $50 \mathrm{mg} \mathrm{L}^{-1}$ )

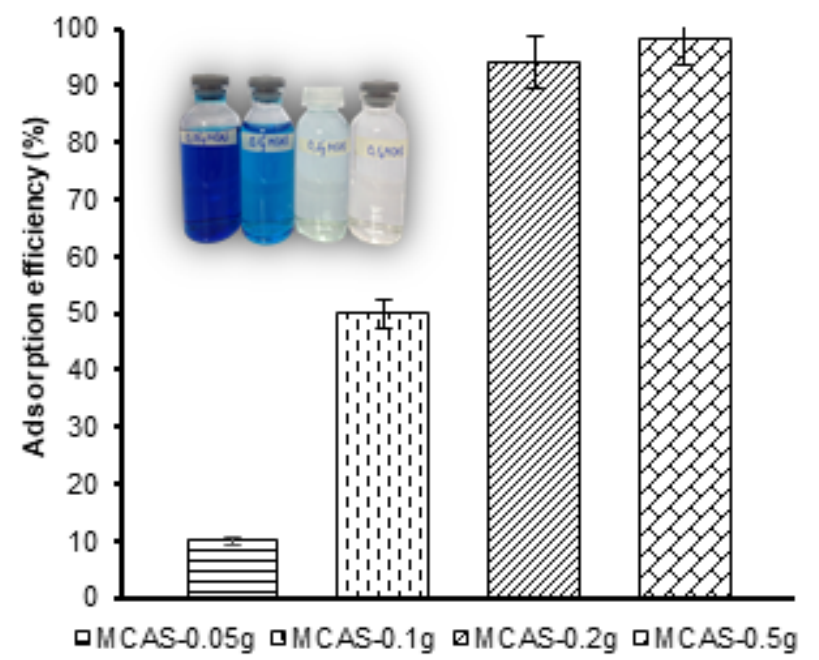

Fig 7. Adsorption kinetics of MB onto MCAS at different amounts of adsorbent (solution volume: $50 \mathrm{~mL}$; time: $30 \mathrm{~min}$; and $\mathrm{MB}$ concentration of $50 \mathrm{mg} \mathrm{L}^{-1}$ ) 
the results indicated that the higher the mass of the adsorbent used, the greater the adsorption capacity of $\mathrm{MB}$ was. Particularly, the adsorption efficiency increased from 18 to $98 \%$ for MB with an increment of the amount of MCAS from 0.05 to $0.2 \mathrm{~g}$. This could be due to the adsorption ability is influenced by the external surface of the prepared nanocomposite. Therefore, an increase in the amount of the nanocomposite ascribed to an increase in surface region and availability of adsorption sites.

\section{Effect of Initial Concentration and Contact Time}

The results showed that the rate of the MB decolonization was faster at the initial stages of the contact time, and then slowed down gradually before reaching equilibrium. As observed, the adsorption efficiency declined when the dye concentration rose. Particularly, the adsorption efficiencies were almost $100 \%$ for the concentration of 30 to $50 \mathrm{mg} \mathrm{L}^{-1}$ and decreased to $87 \%$ for the concentration of $75 \mathrm{mg} \mathrm{L}^{-1}$ (Fig. 8). After the first $10 \mathrm{~min}$, the adsorption efficiency was fairly high owing to a large number of adsorption sites at the beginning. When contact time increased gradually, the number of $\mathrm{MB}$ molecules being accumulated or trapped on the surface of the prepared nanocomposite. Consequently, there was a decline in the adsorption rate at the later stages [26]. In particular, the MB could be adsorbed completely onto the MCAS surface within $15 \mathrm{~min}$. Fig. 9 revealed the decrease in the UV-Vis spectra of MB for adsorption time from initial to $90 \mathrm{~min}$. Additionally, In order to examine the sorption isotherms, the Langmuir model was used. The results exhibited that a very high correlation coefficient $\left(R^{2}>0.9771\right)$ was found, representing that the isotherm obtained for the adsorption of MB effluent followed the Langmuir model (Fig. 8).

\section{Effect of pH Value on the Removal of MB}

The effect of initial $\mathrm{pH}$ on the adsorption capacity of MB onto MCAS was carried out at various $\mathrm{pH}$ values in the range of 3-9. These results expressed that at lower $\mathrm{pH}$, the existence of excess $\mathrm{H}_{3} \mathrm{O}^{+}$ions resulted in a high capacity to protonate carboxylate functional group $\left(-\mathrm{COO}^{-}\right)$on the adsorbent to form more the protonated form $(-\mathrm{COOH})$, leading to a decline in the number of negative charges. Therefore, there might be fewer possibilities to favor positively charged dyes in the acidic medium [27]. When the $\mathrm{pH}$ is increased, the surface area of materials with negative charge significantly increased so that it is more likely to attract more positively charged dyes like MB, (Fig. 10).

\section{Effect of Dye Structure}

It has been reported that the chemical structure of dyes also influences directly on the adsorption capacity of the nanocomposite. Fig. 11 showed that MCAS performed high adsorption capacity with MB, CY51, BS46 and low adsorption capacity with RR198. It is believed that the

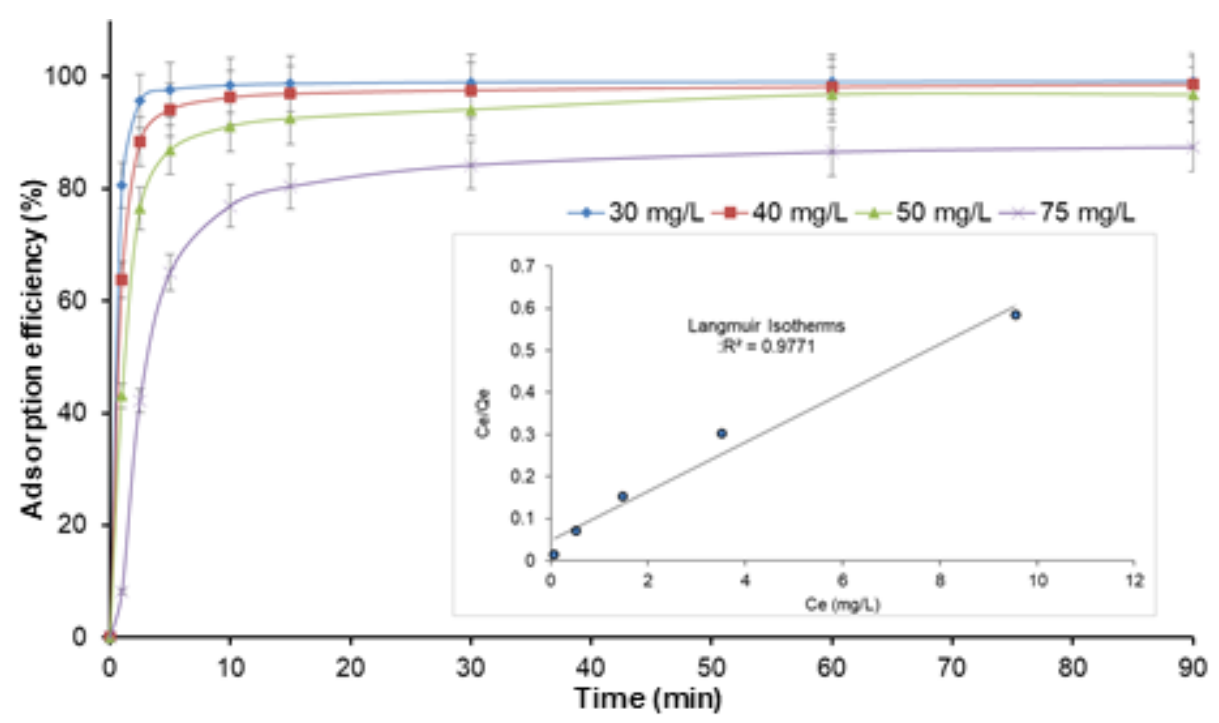

Fig 8. Adsorption kinetics of MB onto MCAS at different initial concentrations (0.2 g MCAS; solution volume: $50 \mathrm{~mL}$ ) 


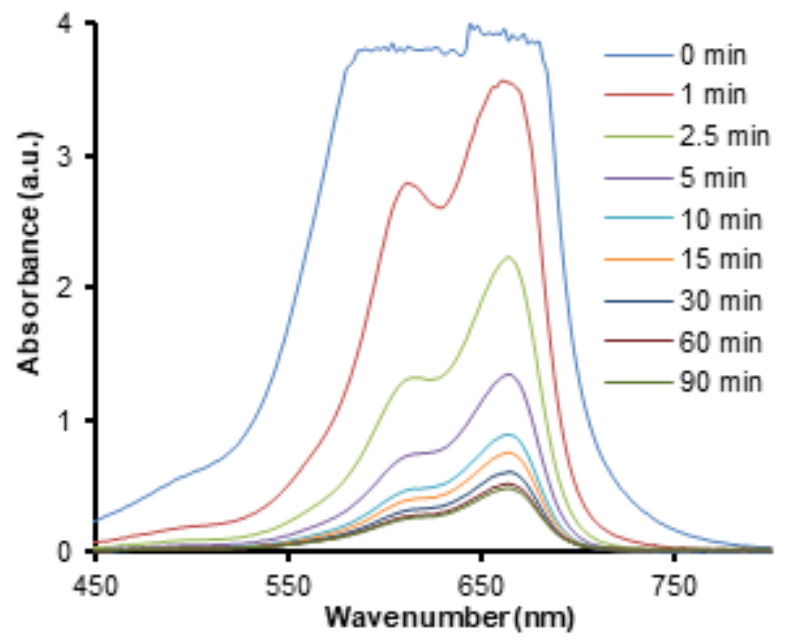

Fig 9. Time-dependent UV-Vis absorption spectra of $M B$ (0.2 $\mathrm{g}$ of MCAS, solution volume: $50 \mathrm{~mL}$, initial $\mathrm{MB}$ concentration: $75 \mathrm{mg} \mathrm{L}^{-1}$ )

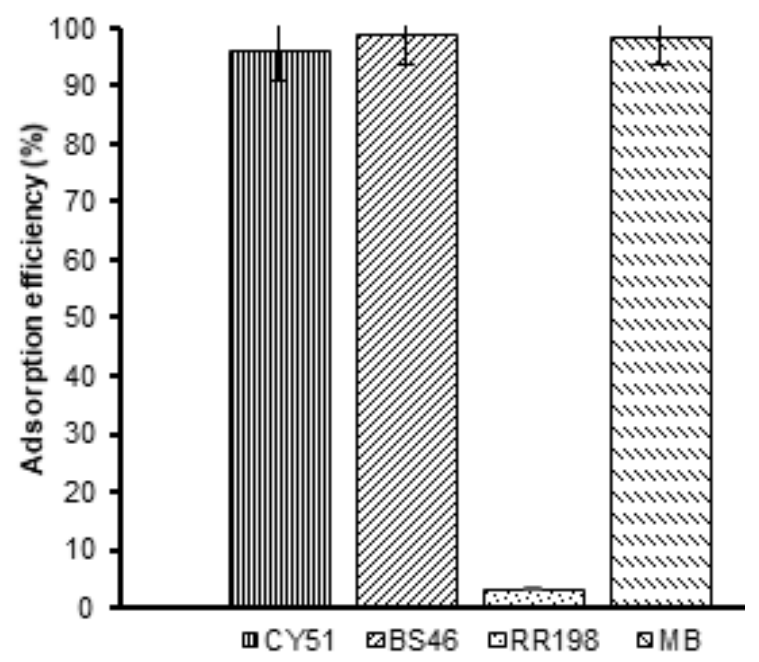

Fig 11. Effect of various dyes structure on adsorption efficiency of MCAS ( $0.2 \mathrm{~g}$ MCAS; solution volume: $50 \mathrm{~mL}$, and concentration of $50 \mathrm{mg} \mathrm{L}^{-1}$ )

phenomenon could be explained due to the difference in the structure of dye molecules. RR198 is an anionic dye with a great number of negative charges while MB, CY51, and BS46 are cationic dyes with the positively charged surface. For this reason, three types of dye molecules MB, CY51 and BS46 can be trapped to the negatively charged surface of the nanocomposite.

\section{- CONCLUSION}

In this present study, acid-treated sugarcane bagasse was prepared with the assistance of microwave irradiation,

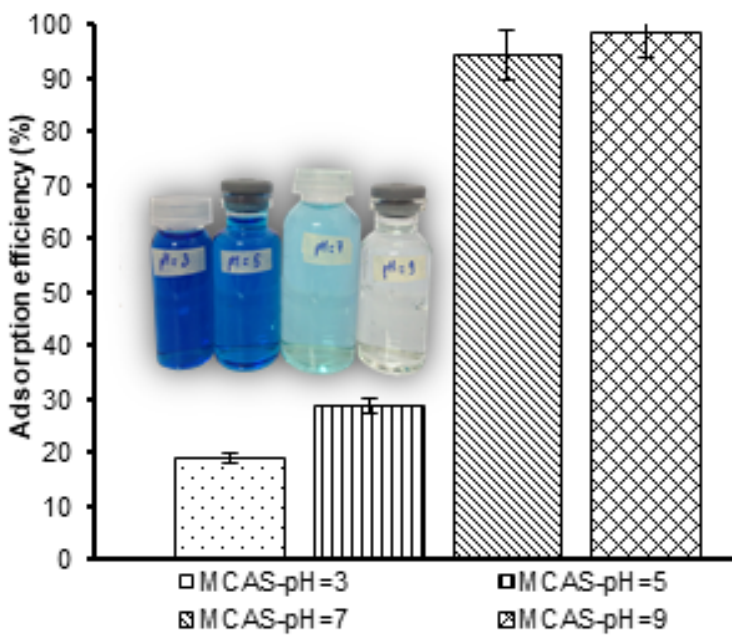

Fig 10. Effect of initial $\mathrm{pH}$ on the adsorption of $\mathrm{MB}$ onto MCAS (0.2 g MCAS; solution volume: $50 \mathrm{~mL}$ and concentration of $50 \mathrm{mg} \mathrm{L}^{-1}$ )

and then a novel magnetic sugarcane bagasse nanocomposite was successfully synthesized by a simple precipitation method. The results indicated that $12.42 \mathrm{mg} / \mathrm{g}$ (98\%) of the methylene blue was removed after $30 \mathrm{~min}$. Additionally, MCAS exhibited a much better capacity in the removal of MB in alkaline milieu than in acidic milieu. Moreover, the higher removal capacity was also observed for MB, CY51, and BS46 dyes in comparison with RR198. The magnetic citric acid-modified sugarcane bagasse showed a much better performance in adsorbing MB than that of natural sugarcane bagasse.

\section{- ACKNOWLEDGMENTS}

The authors would like to thank the Industrial University of Ho Chi Minh City, Vietnam for financial support in 2019 (code: 19.2H01).

\section{- REFERENCES}

[1] Chung, K.T., 2016, Azo dyes and human health: A review, J. Environ. Sci. Health., Part C Environ. Carcinog. Ecotoxicol. Rev., 34 (4), 233-261.

[2] United Nations World Water Assessment Programme, 2017, Wastewater: The untapped resource, The United Nations World Water Development Report, UNESCO, Paris.

[3] Sivaram, N.M., Gopal, P.M., and Barik, D., 2019, "Toxic Waste from Textile Industries" in Energy 
from Toxic Organic Waste for Heat and Power Generation, $1^{\text {st }}$ Ed., Eds. Barik, D., Woodhead Publishing, United Kingdom, 43-54.

[4] Tahir, H., Sultan, M., Akhtar, N., Hameed, U., and Abid, T., 2016, Application of natural and modified sugar cane bagasse for the removal of dye from aqueous solution, J. Saudi Chem. Soc., 20 (Suppl. 1), S115-S121.

[5] Ozturk, E., Karaboyacı, M., Yetis, U., Yigit, N.O., and Kitis, M., 2015, Evaluation of integrated pollution prevention control in a textile fiber production and dyeing mill, J. Cleaner Prod., 88, 116-124.

[6] Karamah, E.F., and Nurcahyani, P.A., 2018, Degradation of Blue KN-R dye in batik effluent by an advanced oxidation process using a combination of ozonation and hydrodynamic cavitation, Indones. J. Chem., 19 (1), 41-47.

[7] Holkar, C.R., Jadhav, A.J., Pinjari, D.V., Mahamuni, N.M., and Pandit, A.B., 2016, A critical review on textile wastewater treatments: Possible approaches, $J$. Environ. Manage., 182, 351-366.

[8] Katheresan, V., Kansedo, J., and Lau, S.Y., 2018, Efficiency of various recent wastewater dye removal methods: A review, J. Environ. Chem. Eng., 6 (4), 4676-4697.

[9] Singh, R.L., Singh, P.K., and Singh, R.P., 2015, Enzymatic decolorization and degradation of azo dyes - A review, Int. Biodeterior. Biodegrad., 104, 21-31.

[10] Bazrafshan, E., Alipour, M.R., and Mahvi, A.H., 2016, Textile wastewater treatment by application of combined chemical coagulation, electrocoagulation, and adsorption processes, Desalin. Water Treat., 57 (20), 9203-9215.

[11] Salgot, M., and Folch, M., 2018, Wastewater treatment and water reuse, Curr. Opin. Environ. Sci. Health, 2, 64-74.

[12] Nguyen, V.C., Hieu, T.Q., Thien, P.T., Vu, L.D., and Tan, L.V., 2017, Reusable starch-graftpolyaniline/ $\mathrm{Fe}_{3} \mathrm{O}_{4}$ composite for removal of textile dyes, Rasayan J. Chem., 10 (4), 1446-1454.

[13] Ahmad, T., and Danish, M., 2018, Prospects of banana waste utilization in wastewater treatment: A review, J. Environ. Manage., 206, 330-348.
[14] Ahsan, M.A., Katla, S.K., Islam, M.T., HernandezViezcas, J.A., Martinez, L.M., Díaz-Moreno, C.A., Lopez, J., Singamaneni, S.R., Banuelos, J., GardeaTorresdey, J., and Noveron, J.C., 2018, Adsorptive removal of methylene blue, tetracycline and $\mathrm{Cr}(\mathrm{VI})$ from water using sulfonated tea waste, Environ. Technol. Innovation, 11, 23-40.

[15] De Gisi, S., Lofrano, G., Grassi, M., and Notarnicola, M., 2016, Characteristics and adsorption capacities of low-cost sorbents for wastewater treatment: A review, Sustainable Mater. Technol., 9, 10-40.

[16] Said, A.A., El-Wahab, M.M.M.A., Soliman, S.A., and Aly, A.A.M., 2010, Potential application of propionic acid modified sugarcane bagasse for removal of basic and acid dyes from industrial wastewater, International Conference on Environmental Engineering and Applications, Singapore, 10-12 September 2010, 154-156.

[17] Ekpete, O.A., Kpee, F., Amadi, J.C., and Rotimi, R.B., 2010, Adsorption of chromium(VI) and zinc(II) ions on the skin of orange peels (Citrus sinensis), J. Nepal Chem. Soc., 26, 31-39.

[18] Zhang, J., Li, Y., Zhang, C., and Jing, Y., 2008, Adsorption of malachite green from aqueous solution onto carbon prepared from Arundo donax root, J. Hazard. Mater., 150 (3), 774-782.

[19] Hasanpoor, M., Aliofkhazraei, M., and Delavari, H., 2015, Microwave-assisted synthesis of zinc oxide nanoparticles, Procedia Mater. Sci., 11, 320-325.

[20] Valdez, J., and Gómez, I., 2016, One-step green synthesis of metallic nanoparticles using sodium alginate, J. Nanomater., 2016, 9790345.

[21] Prasiwi, A.D., Trisunaryanti, W., Triyono, T., Falah, I.I., Santi, D., and Marsuki, M.F., 2019, Synthesis of mesoporous carbon from Merbau wood (Intsia spp) by microwave method as $\mathrm{Ni}$ catalyst support for a-cellulose hydrocracking, Indones. J. Chem., 19 (3), 575-582.

[22] Fideles, R.A., Ferreira, G.M.D., Teodoro, F.S., Adarme, O.F.H., da Silva, L.H.M., Gil, L.F., and Gurgel, L.V.A., 2018, Trimellitated sugarcane bagasse: A versatile adsorbent for removal of cationic dyes from aqueous solution. Part I: Batch 
adsorption in a monocomponent system, J. Colloid Interface Sci., 515, 172-188.

[23] Elias, M.M.C., Ferreira, G.M.D., de Almeida, F.T.R., Rosa, N.C.M., Silva, I.A., Filgueiras, J.G., de Azevedo, E.R., da Silva, L.H.M., Melo, T.M.S., Gil, L.F., and Gurgel, L.V.A., 2019, Synthesis and application of sugarcane bagasse cellulose mixed esters. Part I: Removal of $\mathrm{Co}^{2+}$ and $\mathrm{Ni}^{2+}$ from single spiked aqueous solutions in batch mode using sugarcane bagasse cellulose succinate phthalate, J. Colloid Interface Sci., 533, 678-691.

[24] Zheng, Y., Cheng, Y., Bao, F., and Wang, Y., 2006, Synthesis and magnetic properties of $\mathrm{Fe}_{3} \mathrm{O}_{4}$ nanoparticles, Mater. Res. Bull., 41 (3), 525-529.
[25] Begum, H.A., and Bin Mahbub, M.K., 2013, Effectiveness of carboxymethyl cellulose for the removal of methylene blue from aqueous solution, Dhaka Univ. J. Sci., 61 (2), 193-198.

[26] Uddin, M.T., Islam, M.A., Mahmud, S., and Rukanuzzaman, M., 2009, Adsorptive removal of methylene blue by tea waste, J. Hazard. Mater., 164 (1), 53-60.

[27] Sartape, A.S., Mandhare, A.M., Jadhav, V.V., Raut, P.D., Anuse, M.A., and Kolekar, S.S., 2017, Removal of malachite green dye from aqueous solution with adsorption technique using Limonia acidissima (wood apple) shell as low cost adsorbent, Arabian J. Chem., 10 (Suppl. 2), S3229-S3238. 